\title{
Caloric Adequacy in the First Week of Mechanically Ventilated Patients has No Impact on Long-term Daily Life Activities
}

\author{
Angela P Dariano ${ }^{1}$, Cecilia FL Couto ${ }^{2}$, Bibiana A Rubin ${ }^{3}$, Marina V Viana ${ }^{4}$, Gilberto Friedman ${ }^{5}$
}

\begin{abstract}
Aim and objective: The aim and objective of this study is to test the effect of an optimized caloric supply in the first week of intensive care unit (ICU) stay in mechanically ventilated patients on the ability to perform their activities of daily living (ADL) in the long-term.

Materials and methods: A prospective observational study comparing patients who achieved an adequate caloric target ( $\geq 80 \%$ ) vs those whose target was inadequate $(<80 \%)$. The primary outcome under study is the instrumental ADL (IADL) scale after 6 months of discharge.

Results: Ninety-two patients were evaluated in the ICU and 50 were alive at 6 months. Follow-up was lost for 3 patients and 47 patients were evaluated at ICU and after 6 months. Thirty-four patients reached the energetic target and 13 did not reach it. There was no significant variation in IADL.

Conclusion: The energy adequacy in the first week of hospitalization was achieved by most survivors; however, this conduct does not seem to have influenced the ability to perform ADL after 6 months of discharge.

Keywords: Caloric target, Critical care medicine, Daily life activities, Long-term survival, Mechanical ventilation, Nutrition.

Indian Journal of Critical Care Medicine (2020): 10.5005/jp-journals-10071-23674
\end{abstract}

\section{INTRODUCTION}

The decline of survivors of a critical condition is a major challenge and is not yet fully understood. ${ }^{1,2}$ Some studies point out deleterious consequences such as persistent functional decline, hospital readmissions, pain, and unproductivity. ${ }^{3-6}$ There are few studies that investigate which interventions applied in the intensive care unit (ICU) have the potential to help the survivors' recovery after hospital discharge. The most studied interventions are focused on physical rehabilitation and with unclear results. ${ }^{7}$

With regard to nutritional therapy (NT), the existing literature is controversial in determining the influence of energy adequacy on long-term clinical outcomes, such as functional recovery and quality of life. Wei et al. identified better functional capacity and physical performance at 3 months of observation in the group that received a $25 \%$ higher caloric intake. ${ }^{8}$ Yeh et al. associated the accumulation of an energy deficit of $>6,000 \mathrm{kcal}$ or $>300 \mathrm{~g}$ of protein, with a lower rate of hospital discharge. ${ }^{9}$ However, other studies fail to show the benefit of full and early nutrition. A clinical study shows that malnutrition is associated with lower long-term mortality ${ }^{10}$ and another showed no difference in mortality or quality of life. ${ }^{11}$ The lack of generalization, the inclusion of patients with "low nutritional risk", and the methodological issues of these studies, however, are factors that make the interpretation and applicability of these data difficult. ${ }^{12,13}$ Our group recently published a pilot study, in which we were unable to demonstrate that critically ill patients who receive a caloric intake of $70 \%$ or more, in the first 72 hours of hospitalization have better outcomes in the short-term or after 1 year (functional capacity and mortality). ${ }^{14}$ This study has some limitations such as the lack of comparison of the patient's functional capacity, before and after ICU admission, and lack of assessment of the patient's nutritional status or other nutritional risk scores on admission to the
1,2,5 Programa de Pós-graduação em Ciências Pneumológicas, Universidade Federal do Rio Grande do Sul, Porto Alegre, Rio Grande do Sul, Brazil

${ }^{3,4}$ Hospital de Clínicas de Porto Alegre, Porto Alegre, Rio Grande do Sul, Brazil

Corresponding Author: Gilberto Friedman, Programa de Pósgraduação em Ciências Pneumológicas, Universidade Federal do Rio Grande do Sul, Porto Alegre, Rio Grande do Sul, Brazil, Phone: +5551999352443, e-mail: gfriedman@hcpa.edu.br

How to cite this article: Dariano AP, Couto CFL, Rubin BA, Viana MV, Friedman G. Caloric Adequacy in the First Week of Mechanically Ventilated Patients has No Impact on Long-term Daily Life Activities. Indian J Crit Care Med 2020;24(12):1206-1212.

Source of support: Nil

Conflict of interest: None

ICU. Finally, the biggest limitation of the study was the very small number of patients evaluated in the long-term, mainly due to the high mortality observed.

Some randomized studies also fail to demonstrate clinical impact when restrictive nutritional strategies are compared to a standard one. ${ }^{11,15}$ However, some authors attribute these findings to methodological flaws, since in none of these studies did the nutritional needs of patients be assessed individually as in the pilot TICACOS study. ${ }^{16}$ Nevertheless, a randomized study conducted by Allingstrup and collaborators, demonstrated that an early and individualized nutritional strategy, guided by indirect calorimetry and nitrogen balance, did not result in improvement of the physical component of quality of life after 6 months of discharge. ${ }^{15}$ 
Therefore, the impact of early energy adequacy on long-term clinical outcomes remains uncertain. The primary objective of this study was to test the effect of an energy input $\geq 80 \%$ of the target in the first week of ICU stay on the survivors' ability to perform activities of daily living (ADL) after 6 months of discharge from the ICU. We hypothesize that mechanically ventilated patients have a better ability to perform daily activities after 6 months of hospital discharge with adequate energetic delivery in the first week of the ICU.

\section{Materials and Methods}

A prospective observational study conducted in an ICU with 43 beds in a university hospital. The study was approved by the local research ethics committee ( $\mathrm{n}$ 903.405). The Informed Consent Form (ICF) was obtained through the legal guardian for the patient, prior to inclusion, which occurred from March 2015 to December 2016.

Adult patients, on mechanical ventilation (MV), with an ICU stay of $>3$ days and receiving exclusive enteral nutritional support were included. Patients with therapeutic limitation due to irreversibility of the condition, enteral nutrition time of $<7$ days, pregnant women, patients with spinal cord trauma, organ donors, and cases of family members' refusal to sign the ICF were excluded.

The demographic and clinical data of the patients included were collected from medical records and stored securely with the aid of a database management platform, Research Electronic Data Capture (REDCap $\left.{ }^{\mathrm{TM}}\right)$. There was a daily observation of dietary prescriptions (energy and protein), the total volume administered, caloric balance, and adverse events associated with enteral nutritional therapy (ENT); as well as other variables associated with daily monitoring of the patient (vasoactive drugs, neuromuscular block, sedation scale, and weaning attempts). The included patients were grouped according to energy adequacy in the first week of hospitalization, with the average nutritional goal in the first week $\geq 80 \%$ considered adequate and $<80 \%$, inadequate.

Nutritional risk was calculated using the modified NUTRIC score. ${ }^{17}$ The ENT target was previously defined by an institutional protocol using the formulas proposed by ESPEN/ASPEN for energy (25 kcal/kg/day) and protein (1.2-1.5 g/ $\mathrm{kg})$; with the exception of individuals with nutritional diagnosis of obesity (grade I, II, or III), whose intervention followed the specific recommendations for this subgroup. ${ }^{18,19}$ The patients' weight was measured on a bed-balance, and upon the finding of edema on physical examination, it was corrected according to the intensity of the edema.

During their stay in the ICU, all patients were submitted to a minimum of three sessions of motor and respiratory physiotherapy in the absence of a medical contraindication. The level of mobilization was discussed by the physician in charge and the physiotherapist and includes from mobilization only in bed to ambulation when the clinical condition allowed it. In wards, physiotherapy sessions were applied twice a day.

\section{Study Outcomes}

The primary outcome under study was the ability to perform ADL through the Instrumental Activities of Daily Living (IADL) proposed by Lawton and Brody ${ }^{20}$ and adapted to the Brazilian population. ${ }^{21}$ Instrumental Activities of Daily Living was applied with the family member at the time of signing the consent form and after 6 months of discharge from the ICU. It consists of simple questions regarding personal care and common activities. According to the score obtained, individuals are classified into total dependence $(=7)$, partial dependence $(>7<21)$, and independence $(=21) .{ }^{20}$ Data on duration of MV, time out of MV, length of stay, and ICU mortality were collected. Patients were followed up for 28 days or until hospital discharge (whichever was earlier). Survivors were contacted 6 months after discharge from the ICU. Demographic data, the reason for admission, acute physiology and chronic health evaluation (APACHE II), and sequential organ failure assessment (SOFA) scores were recorded to assess disease severity. ${ }^{22,23}$

\section{Statistical Analysis}

The results were expressed as mean and standard deviation for continuous variables, with symmetric distribution; and in median and interquartile range for asymmetric variables. Categorical variables were described in relative and absolute frequencies. To compare means, the Student's $t$-test, or one-way analysis of variance (ANOVA) test were applied. In the case of asymmetry, the Mann-Whitney and Kruskal-Wallis tests were used, respectively. While comparing proportions, Pearson's chi-square or Fisher's exact tests were applied. McNemar's Chi-square test verified the variation between the initial and final IADL assessments for survivors. The level of significance adopted was $5 \%$ ( $p \leq 0.05)$.

\section{Results}

In the present study, 129 patients were included, of which 92 were analyzed (Flowchart 1). Among the 59 (64\%) ICU survivors, 47 (51\%) completed follow-up at 6 months. Most patients, 79 $(86 \%)$ started ENT early (Table 1). Table 2 shows that among the 47 survivors evaluated, energy adequacy in the first week of hospitalization was achieved for 34 (72\%) patients. As for protein intake, 27 (42\%) patients were below the recommended

Flowchart 1: Inclusion flow diagram

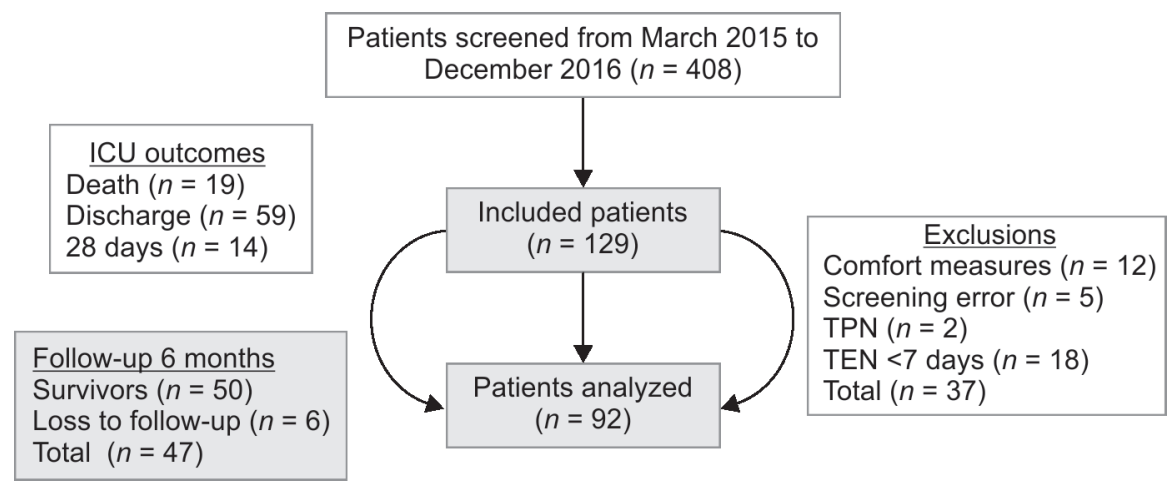


Table 1: Demographic, clinical, and nutritional variables in the first week of hospitalization of survivors in 6 months and non-survivors

\begin{tabular}{|c|c|c|c|c|}
\hline Variables & $A / l(n=92)$ & $\begin{array}{l}\text { Suvivors } 6 \text { months } \\
(n=47)\end{array}$ & $\begin{array}{l}\text { Non-survivors } \\
(n=39)\end{array}$ & pvalue \\
\hline Age (years) & & $56 \pm 17$ & $62 \pm 13$ & 0.079 \\
\hline \multicolumn{5}{|l|}{ Sex-n (\%) } \\
\hline Male & & 19 & 23 & \multirow[t]{2}{*}{0.13} \\
\hline Female & & 28 & 16 & \\
\hline BMI $\left(\mathrm{kg} / \mathrm{m}^{2}\right)$-median (P25-P75) & & $26[23-31]$ & $24[21-28]$ & 0.063 \\
\hline \multicolumn{5}{|l|}{ NUTRIC— $n(\%)$} \\
\hline Low & & 13 & 7 & \multirow[t]{2}{*}{0.318} \\
\hline High & & 34 & 32 & \\
\hline \multicolumn{5}{|l|}{ Sepsis-n (\%) } \\
\hline Yes & & 32 & 30 & \multirow[t]{2}{*}{0.470} \\
\hline No & & 15 & 9 & \\
\hline \multicolumn{5}{|l|}{ Diagnostic classification $-n(\%)$} \\
\hline Clinical & & 38 & 30 & \multirow[t]{3}{*}{0.905} \\
\hline Elective surgery & & 5 & 5 & \\
\hline Emergency surgery & & 4 & 4 & \\
\hline APACHE II & & $23 \pm 10$ & $25 \pm 7$ & 0.502 \\
\hline SOFA & & $9 \pm 3$ & $10 \pm 3$ & 0.709 \\
\hline Duration MV (days) & & $10[8-19]$ & 15 [12-27] & 0.012 \\
\hline Time out of MV (days) & & $4[2-5]$ & $0[0-3]$ & $<0.001$ \\
\hline ICU length of stay (days) & & $17[13-24]$ & $16[13-28]$ & 0.501 \\
\hline \multicolumn{5}{|l|}{ ICU outcome- $n(\%)$} \\
\hline Death & & 0 & 18 & \multirow[t]{3}{*}{$<0.001$} \\
\hline Discharge & & 44 & 10 & \\
\hline 28 days & & 3 & 11 & \\
\hline \multicolumn{5}{|l|}{ Early $\mathrm{EN}-n(\%)$} \\
\hline No & & 4 & 3 & \multirow[t]{2}{*}{0.999} \\
\hline Yes & & 43 & 36 & \\
\hline Time to full EN (days) & & $2.5[2-4]$ & $4[2-4]$ & 0.082 \\
\hline Total kcal/kg delivered in 7 days & & $19 \pm 5$ & $18 \pm 4$ & 0.144 \\
\hline$\%$ adequation $\mathrm{kcal} 7$ days-mean $\pm \mathrm{SD}$ & & 87 [79-90] & 86 [77-89] & 0.668 \\
\hline Proteins $(\mathrm{g} / \mathrm{kg})-$ mean $\pm S D$ & & $1.2 \pm 0.3$ & $1.2 \pm 0.3$ & 0.408 \\
\hline \multicolumn{5}{|c|}{ Classification of the percentage of protein adequacy $-n(\%)$} \\
\hline Adequate & & 27 & 18 & \multirow[t]{2}{*}{0.386} \\
\hline Inadequate & & 20 & 21 & \\
\hline
\end{tabular}

APACHE II, acute physiology and chronic health evaluation II; BMI, body mass index; EN, enteral nutrition; ICU, intensive care unit; MV, mechanical ventilation; NUTRIC score, nutritional risk assessment tool; SOFA, sequential organ failure assessment

minimum dose. The comparison of patients with caloric adequacy vs those with caloric inadequacy shows that the times of MV and ICU, and protein intake were higher for those who had the minimum target reached.

There was no significant variation between the initial IADL and after 6 months for the 47 patients evaluated ( $p=0.940$ ) (Fig. 1). Eight patients improved and six worsened their IADL. Twentynine patients were independent, 15 were partially dependent and only 3 were dependent. For analysis purposes, we grouped the patients as dependent and independent (Table 3). The comparison between dependent and independent patients at 6 months shows no difference for nutritional variables, nutritional risk or severity of disease, and sepsis.

\section{Discussion}

The present study showed that an optimized energy supply ( $\geq 80 \%$ of the estimated target) did not result in any benefit regarding the survivors' ability to perform ADL. This strategy was associated with a longer time spent on MV and a longer ICU stay. The study by Arabi et al. obtained similar outcomes through a caloric intake $>64 \%$ of the estimated target. ${ }^{24}$

In relation to our finding that IADL was not related to caloric intake or even to any nutritional characteristic in the first week of the ICU, the literature presents conflicting findings. ${ }^{15,25}$ Reid et al. demonstrated that, although the use of a hypercaloric formula $(1.5 \mathrm{kcal} / \mathrm{mL})$ in the initial phase of critical illness can optimize 
Table 2: Demographic, clinical, and nutritional variables in the first week of hospitalization of survivors assessed after 6 months

\begin{tabular}{|c|c|c|c|c|}
\hline Variables & All $(n=47)$ & $\begin{array}{l}\text { Adequate caloric target } \\
(n=34)\end{array}$ & $\begin{array}{l}\text { Inadequate caloric target } \\
(n=13)\end{array}$ & $p$ value \\
\hline Age (years) & $56 \pm 17$ & $55 \pm 17$ & $57 \pm 17$ & 0.71 \\
\hline \multicolumn{5}{|l|}{ Sex-n (\%) } \\
\hline Male & $28(60)$ & $21(45)$ & $7(15)$ & \\
\hline Female & $19(40)$ & $13(28)$ & $6(13)$ & 0.87 \\
\hline BMI $\left(\mathrm{kg} / \mathrm{m}^{2}\right)$-median (P25-P75) & $26[23-31]$ & $25[24-30]$ & $28[22-32]$ & 0.73 \\
\hline \multicolumn{5}{|l|}{ NUTRIC $-n(\%)$} \\
\hline Low & $13(28)$ & $8(17)$ & $5(11)$ & 0.47 \\
\hline High & $34(72)$ & $26(55)$ & $8(17)$ & \\
\hline \multicolumn{5}{|l|}{ Sepsis-n (\%) } \\
\hline Yes & 32 & $25(53)$ & $7(15)$ & 0.29 \\
\hline No & 15 & $9(19)$ & $6(13)$ & \\
\hline \multicolumn{5}{|l|}{ Diagnostic classification $-n(\%)$} \\
\hline Clinical & $38(81)$ & $29(62)$ & $9(19)$ & 0.23 \\
\hline Elective surgery & $5(11)$ & $2(4)$ & $3(6)$ & \\
\hline Emergency surgery & 4 & $3(6)$ & 1 & \\
\hline APACHE II & $23 \pm 10$ & $25 \pm 9$ & $20 \pm 10$ & 0.16 \\
\hline SOFA & $10 \pm 3$ & $10 \pm 4$ & $9 \pm 3$ & 0.34 \\
\hline Duration MV (days) & $10[8-19]$ & $16[10-21]$ & $7[6-8]$ & 0.001 \\
\hline Time out of MV (days) & $4[2-5]$ & $3[2-5]$ & $4[3-5]$ & 0.47 \\
\hline ICU length of stay (days) & 17 [13-24] & $21[15-24]$ & $11[10-13]$ & 0.001 \\
\hline \multicolumn{5}{|l|}{ Early EN-n (\%) } \\
\hline No & $4(8)$ & $3(6)$ & $1(2)$ & 0.99 \\
\hline Yes & $43(92)$ & $31(66)$ & $12(25)$ & \\
\hline Time to full EN (days) & & $3[2-4]$ & $2[1-3]$ & 0.51 \\
\hline Daily calories (kcal/kg/day) & $19 \pm 5$ & $20 \pm 4$ & $16 \pm 4$ & 0.002 \\
\hline Percent daily calorie target (kcal) & $84[74-88]$ & 86 [84-90] & $71[62-74]$ & 0.001 \\
\hline Proteins (g/kg) & $1.2 \pm 0.3$ & $1.2 \pm 0.3$ & $1.0 \pm 0.3$ & 0.02 \\
\hline \multicolumn{5}{|l|}{ Protein adequacy intake $-n(\%)$} \\
\hline Adequate & $14(30)$ & $13(28)$ & $3(6)$ & 0.49 \\
\hline Inadequate & $31(66)$ & $21(45)$ & $10(21)$ & \\
\hline
\end{tabular}

APACHE II, acute physiology and chronic health evaluation II; BMI, body mass index; EN, enteral nutrition; ICU, intensive care unit; MV, mechanical ventilation; NUTRIC score, nutritional risk assessment tool; SOFA, sequential organ failure assessment

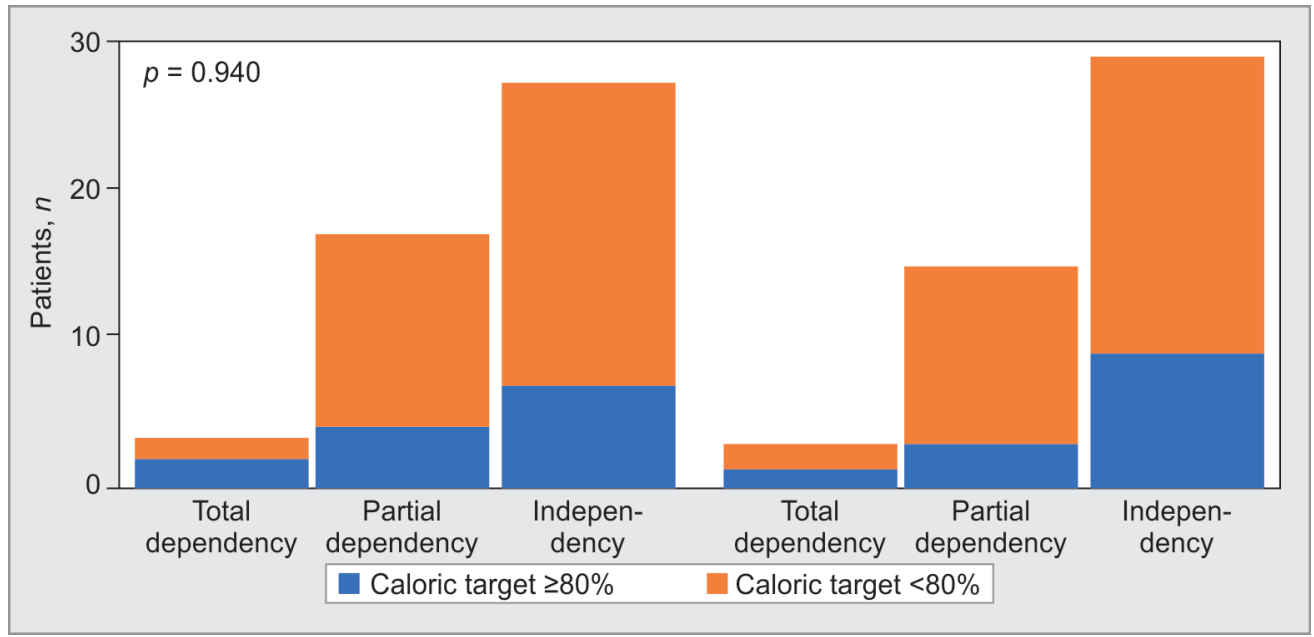

Fig. 1: Instrumental activity of daily living scale (IADL): initial and after 6 months discharge from the ICU (McNamar test) 
Adequate Caloric Intake has No Effect on Mechanically Ventilated Survivors

Table 3: Relationship between dependence for daily activities and nutritional, severity, and clinical variables in the ICU

\begin{tabular}{|c|c|c|c|}
\hline & Dependents $(N=18)$ & Independents $(N=29)$ & $p$ value \\
\hline Caloric target & & & 0.739 \\
\hline Adequate & 14 & 20 & \\
\hline Inadequate & 4 & 9 & \\
\hline Daily caloric intake (kcal/kg/day) & $20 \pm 4$ & $19 \pm 5$ & 0.434 \\
\hline Protein target & & & 0.999 \\
\hline Adequate & 12 & 19 & \\
\hline Inadequate & 6 & 10 & \\
\hline Proteins (g/kg) & $1.2 \pm 0.3$ & $1.1 \pm 0.3$ & 0.751 \\
\hline NUTRIC & & & 0.739 \\
\hline Low risk & 4 & 9 & \\
\hline High risk & 14 & 20 & \\
\hline NUTRIC & $6 \pm 2$ & $5 \pm 2$ & 0.689 \\
\hline BMI & $28[22-31]$ & $25[24-31]$ & 0.801 \\
\hline APACHE II & $25 \pm 10$ & $22 \pm 9$ & 0.260 \\
\hline SOFA & $10 \pm 3$ & $9 \pm 3$ & 0.176 \\
\hline Duration of MV (days) & $14[0-20]$ & $10[8-18]$ & 0.284 \\
\hline Time out of MV (days) & $4[3-6]$ & $3[2-5]$ & 0.264 \\
\hline ICU length of stay (days) & $19 \pm 5$ & $17 \pm 6$ & 0.140 \\
\hline Sepsis & & & 0.753 \\
\hline Yes & 13 & 19 & \\
\hline No & 5 & 10 & \\
\hline
\end{tabular}

APACHE II, acute physiology and chronic health evaluation II; BMI, body mass index; ICU, intensive care unit; MV, mechanical ventilation; NUTRIC score, nutritional risk assessment tool; SOFA, sequential organ failure assessment

energy supply, this practice did not influence clinical outcomes 1 year after discharge. ${ }^{25}$ In a clinical trial, conducted by Allingstrup and colleagues, the effect of an individualized nutritional strategy, guided by indirect calorimetry, was compared to standard nutrition (25 kcal $/ \mathrm{kg} / \mathrm{day}) .{ }^{15}$ Although the intervention group received a higher caloric and protein intake, this practice did not result in an improvement in the physical component of quality of life after 6 months of discharge. On the other hand, Wei et al. achieved a better physical and functional recovery at 3 months of follow-up in patients who received a $25 \%$ greater caloric intake, but this effect was not observed at 6 months. ${ }^{8}$

Current guidelines recommend commencing enteral feeding early with caloric energy targets reached within 3 days in the course of ICU stay. This has been associated with a decrease in infections. ${ }^{26}$ In our study, $90 \%$ of the patients received early feeding. Recommendations for protein intake are $1.3 \mathrm{~g} / \mathrm{kg} / \mathrm{day}$, combined with an exercise program. ${ }^{27}$ Our patients received a mean of 1.2 $\mathrm{g} / \mathrm{kg} /$ day with motor and respiratory rehabilitation 3 times a day in the ICU, including cicloergometer. Interestingly, patients who reached the nutritional target also received a greater protein intake and even so, an improvement in their ability to perform ADL was not observed. Sarcopenic patients have an increased risk of mortality, but the effect of high protein intake in critically ill patients is controversial. ${ }^{15}$ Exercise alone seems to enhance short-term recovery and quality of life. ${ }^{28}$ Early physical exercise for patients with septic shock was recently shown to preserve muscle fiber cross-sectional area, suggesting that autophagia was suppressed by exercise.

The definition of the adequacy of the caloric target is a controversial topic. ASPEN/ESPEN guidelines define a low-calorie diet when $70 \%$ or less of the caloric target is reached when using formulas. Our nutrition service uses $80 \%$ of the target as an institutional adequacy criterion. One could argue that the hypocaloric group may have received enough calories $(>70 \%)$ and this could explain the lack of differences. Of the 13 patients who received a low-calorie diet $(<80 \%)$, in 8 patients the proportion of the target did not exceed the $70 \%$ defined in the guidelines.

Providing early optimized nutrition does not seem to prevent patients from becoming chronic critically ill, as our two studies show. Among the possible explanations of these results can be considered the early endogenous production of glucose that covers two-thirds of the energy expenditure during the first days ${ }^{29}$ in response to acute illness. Also, complete enteral feeding is not always tolerated, as shown by the NUTRIREA-2 study. ${ }^{30}$

Entering acute illness with deficits such as weight loss, being older or malnourished, seems to constitute a metabolic disadvantage that threatens the patient's responsiveness and survival and in these patients, inadequate nutrition can be a risk of mortality and who knows a prognosis more reserved in the survivors. ${ }^{31,32}$ The best way to assess nutritional risk in critically ill patients is not yet defined, but there are several tools described as the use of BMI, NUTRIC, NRS. ${ }^{33}$ Furthermore, even for malnourished patients, the best nutritional strategy still needs to be defined. ${ }^{34}$ The population of our study consists of a group of severely ill patients, with high APACHE II and high SOFA, which for this reason could present a greater benefit of nutritional optimization.

Our study reinforces that there is a need to better study nutritional strategies in critically ill patients and their impact on hospital and long-term outcomes. Thus, it is important to note that these results do not negate the hypothesis that patients at higher nutritional risk benefit from individualized NT. ${ }^{35}$ Exposing high-risk patients to malnutrition can further deteriorate their 
responsiveness and possibly favor the development of chronic critical illness. ${ }^{36}$

The present study has some limitations, such as the observational design, the reduced number of participants in each group, and the caloric goal estimated using a formula. In addition, there was no follow-up of records regarding the reintroduction of the oral route or nutritional interventions performed after discharge from the ICU until the assessment of IADL after 6 months. Finally, it is possible to state that the complexity of the critical patient is such that it is unlikely that the simple nutritional adjustment applied in the first week will influence the prognosis, particularly when most patients are septic.

\section{ConCLUSION}

The results of this pilot study do not demonstrate that mechanically ventilated patients who receive an enteral caloric intake $\geq 80 \%$ in the first week of hospitalization have better long-term outcomes. The influence of energy adequacy in the initial phase of hospitalization of critically ill patients on long-term clinical outcomes remains uncertain.

\section{HighLightS}

Adequate early caloric intake has no benefit for mechanically ventilated survivors in long-term. We evaluated mechanically ventilated patients who survived and who received at least $80 \%$ of their calorie targets in the first week of ICU. These patients were compared with those who did not receive the proposed caloric target in relation to their ability to perform their daily activities after 6 months of discharge from the ICU. We found no difference between the two groups. The role of full and early nutrition for acutely critically ill patients remains uncertain.

\section{References}

1. Biason L, Teixeira C, Haas JS, Cabral CDR, Friedman G. Effects of sepsis on morbidity and mortality in critically ill patients 2 years after intensive care unit discharge. Am J Crit Care 2019;28(6):424-432. DOI: 10.4037/ajcc2019638.

2. Robinson CC, Rosa RG, Kochhann R, Schneider D, Sganzerla D, Dietrich C, et al. Quality of life after intensive care unit: a multicenter cohort study protocol for assessment of long-term outcomes among intensive care survivors in Brazil. Rev Bras Ter Intensiva 2018;30(4):405-413. DOI: 10.5935/0103-507X.20180063.

3. Langerud AK, Rustoen T, Smastuen MC, Kongsgaard U, Stubhaug A. Intensive care survivor-reported symptoms: a longitudinal study of survivors' symptoms. Nurs Crit Care 2018;23(1):48-54. DOI: 10.1111/ nicc. 12330.

4. Cheung AM, Tansey CM, Tomlinson G, Diaz-Granados N, Matté A, Barr $A$, et al. Two-year outcomes, health care use, and costs of survivors of acute respiratory distress syndrome. Am J Respir Crit Care Med 2006;174(5):538-544. DOI: 10.1164/rccm.200505-6930C.

5. Iwashyna TJ, Ely EW, Smith DM, Langa KM. Long-term cognitive impairment and functional disability among survivors of severe sepsis. JAMA 2010;304(16):1787-1794. DOI: 10.1001/jama.2010.1553.

6. Kamdar BB, Huang M, Dinglas VD, Colantuoni E, von Wachter TM, Hopkins RO, et al. Joblessness and lost earnings after acute respiratory distress syndrome in a 1-year national multicenter study. Am J Respir Crit Care Med 2017;196(8):1012-1020. DOI: 10.1164/ rccm.201611-2327OC.

7. Tipping CJ, Harrold M, Holland A, Romero L, Nisbet T, Hodgson $\mathrm{CL}$. The effects of active mobilisation and rehabilitation in ICU on mortality and function: a systematic review. Intensive Care Med 2017;43(2):171-183. DOI: 10.1007/s00134-016-4612-0.
8. Wei X, Day AG, Ouellette-Kuntz H, Heyland DK. The association between nutritional adequacy and long-term outcomes in critically ill patients requiring prolonged mechanical ventilation: a multicenter cohort study. Crit Care Med 2015;43(8):1569-1579. DOI: 10.1097/ CCM.0000000000001000.

9. Yeh DD, Fuentes E, Quraishi SA, Cropano C, Kaafarani H, Lee J, et al. Adequate nutrition may get you home: effect of caloric/ protein deficits on the discharge destination of critically ill surgical patients. JPEN J Parenter Enteral Nutr 2016;40(1):37-44. DOI: 10.1177/0148607115585142.

10. Arabi YM, Tamim HM, Dhar GS, Al Dawood A, Al Sultan M, Sakkijha $\mathrm{MH}$, et al. Permissive underfeeding and intensive insulin therapy in critically ill patients: a randomized controlled trial. Am J Clin Nutr 2011;93(3):569-577. DOI: 10.3945/ajcn.110.005074.

11. Needham DM, Dinglas VD, Bienvenu OJ, Colantuoni E, Wozniak AW, Rice TW, et al. One year outcomes in patients with acute lung injury randomised to initial trophic or full enteral feeding: prospective follow-up of EDEN randomised trial. BMJ 2013;346(mar19 3):f1532. DOI: 10.1136/bmj.f1532.

12. Weijs PJ, Wischmeyer PE. Optimizing energy and protein balance in the ICU. Curr Opin Clin Nutr Metab Care 2013;16(2):194-201. DOI: 10.1097/MCO.0b013e32835bdf7e.

13. Heyland DK, Wischmeyer PE. Does artificial nutrition improve outcome of critical illness? an alternative viewpoint!. Crit Care 2013;17(4):324. DOI: 10.1186/cc12701.

14. Couto CFL, Dariano A, Texeira C, Silva CHD, Torbes AB, Friedman G. Adequacy of enteral nutritional support in intensive care units does not affect the short- and long-term prognosis of mechanically ventilated patients: a pilot study. Rev Bras Ter Intensiva 2019;31(1): 34-38. DOI: 10.5935/0103-507X.20190004.

15. Allingstrup MJ, Kondrup J, Wiis J, Claudius C, Pedersen UG, HeinRasmussen $\mathrm{R}$, et al. Early goal-directed nutrition versus standard of care in adult intensive care patients: the single-centre, randomised, outcome assessor-blinded EAT-ICU trial. Intensive Care Med 2017;43(11):1637-1647. DOI: 10.1007/s00134-017-4880-3.

16. Singer P, Anbar R, Cohen J, Shapiro H, Shalita-Chesner M, Lev S, et al. The tight calorie control study (TICACOS): a prospective, randomized, controlled pilot study of nutritional support in critically ill patients. Intensive Care Med 2011;37(4):601-609. DOI: 10.1007/s00134-0112146-z.

17. Rahman A, Hasan RM, Agarwala R, Martin C, Day AG, Heyland DK. Identifying critically-ill patients who will benefit most from nutritional therapy: further validation of the "modified NUTRIC" nutritional risk assessment tool. Clin Nutr 2016;35(1):158-162. DOI: 10.1016/j. clnu.2015.01.015.

18. Kreymann KG, Berger MM, Deutz NEP, Hiesmayr M, Jolliet P, Kazandjiev $G$, et al. ESPEN guidelines on enteral nutrition: intensive care. Clin Nutr 2006;25(2):210-223. DOI: 10.1016/j.clnu.2006.01.021.

19. McClave SA, Taylor BE, Martindale RG, Warren MM, Johnson DR, Braunschweig C, et al. Guidelines for the provision and assessment of nutrition support therapy in the adult critically ill patient: Society of Critical Care Medicine (SCCM) and American Society for Parenteral and Enteral Nutrition (A.S.P.E.N.). JPEN J Parenter Enteral Nutr 2016;40(2):159-211. DOI: 10.1177/0148607115621863.

20. Lawton MP, Brody EM. Assessment of older people: self-maintaining and instrumental activities of daily living. Gerontologist 1969;9(3):179186. DOI: 10.1093/geront/9.3_Part_1.179.

21. Farias-Antunez S, Lima NP, Bierhals IO, Gomes AP, Vieira LS, Tomasi E. Disability relating to basic and instrumental activities of daily living: a zopulation-based study with elderly in pelotas, Rio Grande do Sul, Brazil, 2014. Epidemiol Serv Saude 2018;27(2):e2017290.

22. Knaus WA, DraperEA, Wagner DP, Zimmerman JE. APACHE Il: a severity of disease classification system. Crit Care Med 1985;13(10):818-829. DOI: 10.1097/00003246-198510000-00009.

23. Vincent JL, De Mendonca A, Cantraine F, Moreno R, Takala J, Suter PM, et al. Use of the SOFA score to assess the incidence of organ dysfunction/failure in intensive care units: results of a multicenter, 
prospective study. Crit Care Med 1998;26(11):1793-1800. DOI: 10.1097/00003246-199811000-00016.

24. Arabi YM, Haddad SH, Tamim HM, Rishu AH, Sakkijha MH, Kahoul $\mathrm{SH}$, et al. Near-target caloric intake in critically ill medical-surgical patients is associated with adverse outcomes. JPEN J Parenter Enteral Nutr 2010;34(3):280-288. DOI: 10.1177/0148607109353439.

25. Reid DB, Chapple LS, O'Connor SN, Bellomo R, Buhr H, Chapman $M J$, et al. The effect of augmenting early nutritional energy delivery on quality of life and employment status one year after ICU admission. Anaesth Intensive Care 2016;44(3):406-412. DOI: 10.1177/0310057X1604400309.

26. Reintam Blaser A, Starkopf J, Alhazzani W, Berger MM, Casaer MP, Deane AM, et al. Early enteral nutrition in critically ill patients: ESICM clinical practice guidelines. Intensive Care Med 2017;43(3):380-398. DOI: 10.1007/s00134-016-4665-0.

27. Singer $P$, Blaser AR, Berger MM, Alhazzani W, Calder PC, Casaer MP, et al. ESPEN guideline on clinical nutrition in the intensive care unit. Clin Nutr 2019;38(1):48-79. DOI: 10.1016/j.clnu.2018.08.037.

28. Doiron KA, Hoffmann TC, Beller EM. Early intervention (mobilization or active exercise) for critically ill adults in the intensive care unit. Cochrane Database Syst Rev 2018;3(3):CD010754. DOI: 10.1002/14651858.CD010754.pub2.

29. Berger MM, Pantet $O$, Jacquelin-Ravel $N$, Charrière $M$, Schmidt $\mathrm{S}$, Becce $\mathrm{F}$, et al. Supplemental parenteral nutrition improves immunity with unchanged carbohydrate and protein metabolism in critically ill patients: the SPN2 randomized tracer study. Clin Nutr 2019;38(5):2408-2416. DOI: 10.1016/j.clnu.2018.10.023.
30. Reignier J, Boisramé-Helms J, Brisard L, Lascarrou JB, Ait Hssain A Anguel N, et al. A randomised, controlled, multicentre, open-label, parallel-group study (NUTRIREA-2). Lancet 2017;391(10116):P133P143. DOI: 10.1016/S0140-6736(17)32146-3.

31. Maciel LRMA, Franzosi OS, Nunes DSL, Loss SH, Dos Reis AM, Rubin BA, et al. Nutritional risk Screening 2002 cut-off to identify high-risk is a good predictor of ICU mortality in critically ill patients. Nutr Clin Pract 2019;34(1):137-141. DOI: 10.1002/ncp.10185.

32. Loss SH, Marchese CB, Boniatti MM, Wawrzeniak IC, Oliveira RP, Nunes $\mathrm{LN}$, et al. Prediction of chronic critical illness in a general intensive care unit. Rev Assoc Med Bras (1992) 2013;59(3):241-247. DOI: 10.1016/j. ramb.2012.12.002.

33. Kondrup J, Rasmussen $\mathrm{HH}$, Hamberg O, Stanga Z. Nutritional risk screening (NRS 2002): a new method based on an analysis of controlled clinical trials. Clin Nutr 2003;22(3):321-336. DOI: 10.1016/ S0261-5614(02)00214-5.

34. Viana MV, Tavares AL, Gross LA, Tonietto TA, Costa VL, Moraes $\mathrm{RB}$, et al. Nutritional therapy and outcomes in underweight critically ill patients. Clin Nutr 2020;39(3):935-941. DOI: 10.1016/j. clnu.2019.03.038.

35. Berger MM, Pichard C. Feeding should be individualized in the critically ill patients. Curr Opin Crit Care 2019;25(4):307-313. DOI: 10.1097/MCC.0000000000000625.

36. Viana MV, Pantet $\mathrm{O}$, Bagnoud $\mathrm{G}$, Martinez A, Favre $\mathrm{E}$, Charrière $M$, et al. Metabolic and nutritional characteristics of long-stay critically ill patients. J Clin Med 2019;8(7):985. DOI: 10.3390/ jcm8070985. 